\title{
Establishing a Computer Industry in the Soviet Socialist Republic of Belarus
}

\author{
Yuri Vladimirovich Karpilovitch ${ }^{1}$, Viktor Vladimirovich Przhijalkovskiy ${ }^{2}$, and \\ Gennadiy Dmitrievich Smirnov ${ }^{3}$ \\ ${ }^{1}$ Minsk Institute of Management \\ ${ }^{2,3}$ Scientific Institute of Digital Electronic Computer Technologies \\ przy@yandex.ru
}

\begin{abstract}
Created in the late 1950s in Minsk, for several years the factory for the production of computers occupied a leading position in the Former Soviet Union by the number of general-purpose computers produced. For many years, the Minsk Plant at GK Ordzhonikidze produced about seventy percent of all computers manufactured in the Union. This paper highlights the activities undertaken by the leadership of the Belarusian Republic that contributed to this production. It illustrates the basic technical specifications of computers developed by the Minsk computer factory that includes the Minsk-1, the Minsk2, theMinsk-22, the Minsk-23, and the Minsk-32 machines. This paper also shows the timing of their development, the number of units produced, and the names of the main developers.
\end{abstract}

Keywords: Minsk computer, NIIEVM, Minsk Factory for Computers.

\section{Introduction}

In August 1956, after completion of the creation the first computers in the USSR ("Strela", BESM, M-3, "Ural -1"), the Council of Ministers of the USSR issued the regulation about measures for a considerable increase in the manufacturing of computers in the country. This decision provided the building of several factories for the computer, their modules, and other details. The factory of mathematical machines in Minsk would become one such new factory according to the decision.

The management of Sovnarhoz BSSR, understanding the importance of the new enterprise for a development of the city, allocated a building site for it at a not-yet completed garment factory building on one of city main squares - the Jakub Kolas square. This decision speeded up essentially a formation of the new factory, which they named the "Minsk Factory for Computers" of G.K. Ordzhonikidze.

In 1958, the special design bureau (SDB) was organized at the factory under construction for the manufacture and modernization support of producing computers. SDB staffing also accelerated by the republic and city authorities who invited some tens of experts who already had computer development experience from other cities in the USSR. Among those invited were G.P. Lopato from Moscow, V.J. Simhes, A.I. Bahir, G.K. Stoljarov, and A.P. Zhigalov from Zagorsk, E.I. Sakaev, S.N. Remorov, 
V.V. Przhijalkovsky, V.E. Klochkov, N.A. Maltsev, and R.M. Astsaturov from Noginsk, V.A. Averyanov from Penza, and I.K. Rostovtsev, G.D. Smirnov, and J.G. Bostandzhja from Yerevan. Together with the Minsk experts, they headed the development and computer manufacturing in the SDB and at the factory. It essentially reduced terms of formation of the Minsk industrial complex on computer production. The prestige of the new enterprise and its development control of the authorities attracted attention of the best experts of a city.

The integration within the limits of an enterprise of developing industrial departments played the positive role since the beginning. It allowed combining a process of development of a product with preparation of its serial production that led to essential reduction of terms of producing new computer manufacturing and fast growth of rates of their output.

Resource conflicts between maintenance of current manufacture and development of the next product were resolved by administration (the director was V.K. Goldberg, the chief engineer was N.I. Kiriljuk). In concrete conditions of the Minsk computer factory of G.K. Ordzhonikidze the perspective policy of a management led to that between the development termination (the state tests) and output of the customizing party of computers in some cases (Minsk-1, Minsk-22, Minsk-23, Minsk-32, ES1020, ES-1022) made terms from one to three months. At that time, the terms of development of the next model were under two years, and the estimate budget of development was record-breaking small.

With growth of complexity of computers, and with the advent of new manufacturers (e.g. the Brest electromechanical factory in 1966), with the expansion of the nomenclature of developed products, and with the increase in expenses at development, it became impossible to maintain the developed organizational unity within the limits of an existing economic mechanism. The SDB factory was allocated for independent balance at first (MPB - 1966) and later it received full economic independence (branch NITSEVT - 1969г., NIIEVM - 1972г.)

\section{Before the Minsk Computers}

In the spring of 1959, in response to a post of the chief engineer of SDB of factory of G.K. Ordzhonikidze, they invited G.P. Lopato, one of the developers of the M-3 computer. In 1956, he created the Electro-modeling laboratory of the Academia of Science of the USSR together with the All-Union scientific research institute of electro-mechanics of Academia of Science the USSR. The production facilities were ready to generate computer production; only the staff planned and completed the developments in SDB. In these conditions, the decision of administration to accept the M-3 computer as a starting product was natural and reasonable.

In September of 1959, the factory produced the first computer made completely independently. It was the variant of the computer with operative memory on a magnetic drum. Its speed was only thirty operations per second, but on it, many technological processes were formed; specialists of development and service were staffed and trained. In 1960, the development of for M-3 operative memory on ferrite 
cores in capacity 1024 31-bit words has finished. The work fulfilled by G.P. Lopato, V.J. Simhes, E.I. Sakaev, A.I. Bahir, V.A. Harlap, and V.B. Novysh.

By the end of 1960, they produced twenty-six M-3 computers and from them, ten computers had the ferrite memory, which increased their speed to 1000 operations in one second. Programming M-3 computers was in machine codes in an octal number system. For the Minsk factory, this computer was valuable as it was the starting one. Sadly, its influence on further computer development was almost zero.

\section{Birth of the Minsk Machine}

In August of 1960, they completed the development of the first independent computer the Minsk-1. Its features included 800 lamps (valves or vacuum tubes), 2500 operations per second, ferrite memory with $1 \mathrm{~K}$ words, a word length of 31 bits, a twoaddress instruction set fixed before the high bit, a peripheral memory on the magnetic tape of $64 \mathrm{~K}$ words, punched tape input of 80 words per second, and output to digital printing of 20 words per second. G.K. Lopato was the chief designer of the computer; the main developers were E.I. Sakaev, V.Y. Simhes, A.I. Bahir, V.L. Salov, S.N. Remorov, G.K. Stolyarov, B.I. Tsagelsky, and G.M. Gendelev.

The Minsk-1 computer had no compatibility with the M-3 computer. It inherited from its predecessor only two architectural characteristics: word length and twoaddress instructions. The Minsk-1 computer was produced until 1964 and it had only a few completely compatible modifications during its productive life.

The Minsk-11 computer was intended for seismic information processing and operation with remote users. The chief designer was V.M. Manzhalej. They produced eleven computers of this version. The Minsk-12 computer had the expanded RAM in capacity $2048 \mathrm{~K}$ words and tape drives with a capacity of $100 \mathrm{~K}$ words. The chief designer was V.Y. Simhes. They produced five versions of this computer.

The Minsk-14 and Minsk-16 computers were intended for telemetry information processing, so they included reading devices of for telemetry. The main designers were L.I. Kabernik and V.M. Manzhalej. In all, they produced thirty-six Minsks-14 computers and one Minsk-16 computer.

In addition, they produced the Minsk-1 computer as a system for storage and recognition of fingerprints for the Ministry of Internal Affairs of the USSR. A.M. Tolmachyov was the main designer of this system. In total between 1960 and 1964, they produced 220 Minsk-1 computers. They, along with "Ural" computers, became the most mass produced computers in the country during that period.

They used machine code to program the Minsk-1 computer. A delivery package included a routine library containing about one hundred programs with 7500 commands. During this period at SDB, they carried out the serious operation for developing the first systems of auto-programming; that is, they developed translators for the autocode "engineer" and the autocode for the "economist". They fulfilled the work at the laboratory of programming of SDB led by G.K. Stoljarov, where they grew a whole group of known programmers such as M.S. Margolin, M.E. Nemenman, E.V. Kovalevich, V.I. Tsagelsky, and N.T. Kushnerev. 


\section{The Minsk-2 Series of Computers}

The next development of SDB of the factory of G.K. Ordzhonikidze was the secondgeneration Minsk-2 computer. V.V. Przhijalkovsky was the chief designer of this development. The main developers are V.E. Klochkov, G.D. Smirnov, N.A. Maltsev, A.I. Bahir, J.G. Bostandzhjan, V.K. Nadenenko, G.K. Stoljarov, and M.B. Tyomkin.

The computer was under development between1960 and 1962, at the same time with the Minsk-1 production. The situation did not demand to ensure a software compatibility of these computers. In addition, to ensure such compatibility it would be far from simple, at least because of the hopelessness of a 31-bit grid. For the new computer they used the 37-bit grid that contained the number sign and twelve octal or nine decimal bits of number. With the Minsk-2 computer, a first for Minsk computers, they used floating-point for the representation of numbers; in this connection, they employed seven bits for order representation, including the order sign bit. Other bits in this case represented a mantissa of number with its sign. It provided representation of numbers from $10^{-19}$ to $10^{+19}$, which was quite enough for a general-purpose small computer.

For the first time in domestic computer facilities with the Minsk-2 computer, it provided the processing of the alphanumeric information in an explicit form. In a machine word, six alphanumeric characters occupied places, encoded by the telegraphic code MTK-2. In this case, they used the sign digit to divide documents and messages among them.

The command of the Minsk-2 computer consisted of an opcode (seven bits), the number of the block of the RAM (two bits), the address of an index cell (four bits), and two twelve-bit addresses. Thus, it provided the functioning of 127 commands, 15 index registers, and the addressing of 8196 words in RAM.

Moreover, the two-address command system of the computer contained standard arithmetic commands and input-output commands. The command of the special arithmetic unit provided the realization of operations for double precision; it included the original command of cycle and a variety of the commands essentially accelerating information processing. Of the one hundred commands involved in the computer, forty were arithmetic. Twenty-seven commands were not involved with arithmetic in the Minsk-22 computer; part of these involved the extracodes and the rest were in reserve for the organization of specialized systems.

The designers developed for the Minsk-2 computer a system of semiconductor units based on inexpensive and widespread transistors of type P-16A. The Potentiallypulse system of units used diode-transformer circuits on oxy-ferrite cores. The clock rate of the complex achieved $250 \mathrm{k} \mathrm{Hz}$.

The units were constructed on replaceable cells having double-sided printed circuit wiring and the printing plugs. Out of twenty-three types of cells, five types made $70 \%$ of all the equipment. In total, the computer included 1286 cells that contained 7500 transistors and 18,000 diodes. Thanks to simplicity, cheapness, and reliability, this complex of units was operational for six years in the Minsk-2/22 and Minsk-23 computers.

For the Minsk-2 computer, they developed a ferrite storage device with semiconducting handle. This was perhaps the first semiconductor storage device of size 4096 words in the USSR; A.I. Bahir, J.G. Bostandzhjan, and V.A. Harlap were 
its designers. The RAM worked on ferrite cores of external diameter of $1.4 \mathrm{~mm}$; it had a cycle of 20 microseconds, a latency of 7.5 microseconds and it contained 740 transistors and 1550 diodes. The power consumed by RAM was only 800 watts. At that time in 1962, it was a pioneering and very successful development. The speed of the computer was 5000-6000 two-address operations per second.

They developed for the computer a new tape drive with a bit density of 12 impulses per millimeter and a photo-reading mechanism for paper punched tape working at a speed 800 strings per second. The listing of the alphanumeric linformation was made on the RTA-50 rolled telegraph.

In the Minsk-2 computer, a first for Minsk computers, they used a hardwaresoftware interruption of programs by a method of operation that suspends the arithmetic device. They used it for operations with output devices of the information and operation with "extracodes". Extracodes, or macrocodes, were also an innovation for Minsk computers. Interruption of programs and extracodes were planned ahead and more effectively used in the expanded package of the Minsk-22 computer.

The complete computer consoles had taken 40 square meters of space and it consumed from a three-phase network of 380/220V less than $4 \mathrm{KW}$. The development of the Minsk-2 concluded in September of 1962. In 1963, its production began from the factory of G.K. Ordzhonikidze. By the end of 1964, they produced 118 computers.

By the end of 1964, they completed the operations on developing changes based on the Minsk-2 with three modifications differing in structure of the additional equipment of input and output of the information. The Minsk-26 computer (N.A. Maltsev) and the Minsk-27 (V.E. Klotchkov) were to process telemetry coming from meteorological rockets and of the earth sputniks "Meteor". The Minsk-22 computers (V.K. Nadenenko) to which the Minsk-2 was connected, contained units of input and output of punched cards and also of the alphanumeric printing station contributed to a line of general-purpose computers.

With the Minsk-2/22 computer, it delivered an extensive standard program library (260 programs, 38000 commands), an autocode "Engineer" (AKI) (8000 commands), a system of symbolical coding (SSC), translators from languages of FORTRAN and ALGOL, the translator from language ALGEK (the language uniting properties of languages COBOL and ALGOL-60). A later delivery package included the translator from language COBOL and a data processing system "SAOD" (55 thousand commands). It was the richest package of programs delivered by the manufacturer with the computer in the USSR. In total, they produced 734 Minsk-22 computers, or 852 Minsk-2/22 computers. As a result, the lead positions of the Minsk computers in the country common park of computers had essentially become stronger.

In the mid 1960s, the Western countries produced large product lines of simple and rather inexpensive computers such as the IBM 1401, IBM-1440, and the Gamma-30 for business calculations. These computers featured a decimal-binary number system, word variable length and developed resources for logical processing of the alphanumeric information; these machines essentially raised the efficiency of processing of industrial and commercial information. The developers of the Minsk computers could not pass by the possibility to expand the usage of its products in the industrial sphere.

In 1966, the SDB factory developed the Minsk-23 computer intended for processes of data processing solutions for economical tasks, tasks of statistics, production 
management, and tasks of datalogical characteristics. The chief designer was V.V. Przhijalkovsky; the deputy of the chief designer was G.D. Smirnov.

The speed of the Minsk-23 achieved about 7000 operations per second. RAM capacity was forty thousand, eight-bit characters (bytes). A cycle of operation of the RAM and the computer was 13 microseconds. The capacity of the address storage (intended for storage of addresses of commands and operands, program and informational bases, and current addresses of an exchange with inputloutput devices) was 127 cells on nineteen bits. The number system was decimal-binary, a comma was fixed after low-order digit; the form of representation of numbers and commands was a character sequence of variable length. The quantity of addresses in the command was variable. Addresses of the commands utilized base and index methods. There were commands representing the whole procedures of data processing.

The Minsk-23 had a structure and the command system completely different from existing architectures at that time in the USSR and computers were oriented to do calculations of a scientific and technical nature. The Minsk-23 was the first domestic computer with character logic with a word and command of variable length. The computer had developed a system of interruption and suspensions and a universal link for peripherals. Actually, it used a byte-multiplex channel and a protected area of memory for service programs. One had the possibility of using a considerable quantity of index fields for each program array, special editing commands, and processing of fields of the variable length consisting of alphanumeric characters.

The Minsk-23 computer utilized a multi-program operating system that provided the possibility to run simultaneously three working and five support programs. Thus, it could work in eight directions with 64 peripherals simultaneously. A delivery package contained input equipment from punched cards (600 cards/s), input equipment from a punched tape (1000 strings/s), an alphanumeric printing device (400 strings/minute), a punch of maps (100 cards/min), and a tape punch (80 characters/s).

For the first time in domestic practice, the Minsk-23 used tape storage of rolled type with a bit density of 32 impressions/mm, which was completely compatible with the Western tape storage specifications. M.F. Chalajdjuk and A.M. Titov developed the storage system at the design office of the Industrial Automation with a brigade led by V.G. Makurochkin that made the project conform to industrial norms. For specialized systems using the Minsk-23 computer, they developed a device called "Blank", which read out formalized forms with pencil marks. The chief designer was V.K. Nadenenko; V.E. Klochkov and E.I. Mukhin developed the data communications equipment through telephone channels on a Minsk-1500 machine.

The developed a language of symbolic coding (SSC) from which they made the system software for the Minsk-23 computer. The library of system standard programs, in addition to the units intended for calculation of elementary functions, contained the programs, made carry out calls to input/output devices with code conversion and editing, to the sort utility, to the service program for a tape drive, and to the support programs. The compiler entered into a delivery package from the autocode, the machine-oriented language with a considerable quantity of the macros servicing input-output and a routine library. Additionally, the compiler structure included the loader to prepare loading units. 
For the first time in the USSR, they designed the software structure for a small computer. The Minsk-23 included an operating system, which contained a batch processing screen monitor, a collector-loader, a link for the computer operator, a system for defining failures, and a coordinator for multi-program processing. M.S. Margolin headed the software development for the computer.

Based on the Minsk-23 computer, they developed an automated control system for some firms, including one of the largest in the country - the Novocherkassk electric locomotive factory. Unfortunately, the computer had no expected commercial success. They had made only twenty-eight computers that did not correspond to possibilities of a factory of G.K. Ordzhonikidze. Probably, it is necessary to consider that the main reason for commercial failure of this computer was that the user was not accustomed to it for its main concepts. The absence of compatibility with previous models, insufficient productivity on tasks of scientific and technical nature, and the poor development for firms and organizations that required processing of business information were some reasons for its failure.

\section{The Minsk-3 Series of Computers}

The Minsk-32 computer completed a series of Minsk computers. They developed the computer under the direction of its chief designer, V.V. Przhijalkovsky. In 1968, its production started.

The purpose of the new development was to create a computer that united the best features of the Minsk-23 and Minsk-22M computers with complete compatibility with the latest technology for data mediums and applications. The necessity of support of compatibility with the widespread computer Minsk-22M certainly constrained the possibilities of developing a new logical structure for the Minsk-32. However, the experience with the previous model had shown the importance of such compatibility for the user.

Compatibility support for the Minsk-32, the bit grid of the computer Minsk-22M consisted of 37 saved bits. It saved the formats of numbers with fixed and floatingpoint formats and with formats for all arithmetic and logical commands. Execution of these commands occurred in the same way as with the Minsk-22M. Programs fulfilled the input-output operations, interrupt systems, failure services, and responses to the operator. Thus, the Minsk-32 computer made hardware-software emulation of Minsk22M programs.

The saving of the 37-bit grid complicated seriously the development of logical structure and functionality of the new computer. Nevertheless, it was possible to bring a variety of innovations raising overall performance and expanding functionality in logical structure of the Minsk-32 machine.

First, as an information unit in addition to the 37-bit words appeared a seven-bit character that allowed presentation of 128 code combinations, including the Latin and Russian alphabet. In a word, five characters took places, each addressed separately. Additionally, one could enter operating commands with sequences of bytes of any length; this was similar to the Minsk-23 computer. There were also commands for decimal arithmetic, matching, and editing. Secondly, the computer could receive 
commands in multi-program operating mode, which allowed one to handle four working programs at the same time.

Soon A.I. Bahir and J.G. Bostandzhjan developed a new economical ferrite storage with capacity of 65,536 bytes, with 38-digit words and with a cycle of five microseconds. They also developed logic circuits with new complex units of diodetransformer types and with a clock rate of $600 \mathrm{kHz}$. As a result, the average speed of the computer was 30-35 thousand operations per second, which is almost six times more than the capacity of the Minsk-22M machine.

The essential improvement was introduction in structure of the computer selector, the byte multiplex channels, and a system of universal links with peripherals (SUS $\mathrm{VNU}$ ); this allowed the possibility of connecting to 136 different peripherals in the standard way.

The design used protection frames of memory area for each working program, an address storage device, an effective system of interrupts (suspensions, for the Minsk23), and an electronic time sensor as part of the computer structure. A special commutator allowed uniting complexities to eight Minsk-32 computers for operations over a shared task.

The computer received the "dispatcher" program, which was an advanced tapetype operating system. With the computer, it was able to deliver a system of symbolical coding, a macro generator, and compilers for COBOL, ALGAMS, and FORTRAN languages. The total amount of delivered programs exceeded 500 thousand commands with eight thousand pages of the documentation. M.E. Nemenman headed the software operations; V.J. Pyhtin was the chief designer of the processor.

They manufactured the Minsk-32 computer up until 1975. In all, they manufactured 2,889 computers; as a result, the Minsk-32 became the most widespread general-purpose computer in the USSR.

Moreover, if one is to understand the meaning of a "general-purpose computer", it would be one that has equal or at least close productivity for scientific and datalogical tasks. We must admit that the Minsk-32, before the appearance of ES computers, was a unique computer of a general-purpose capability in the country. For its logical structure, this computer lost nothing to foreign computers of a similar class. In this case, the collective of the Minsk SDB at the end of sixty years was one of the most qualified in the country and the most prepared for the development of the ES computers.

\section{Conclusion}

The mass serial production of the Minsk-32 computer was possible thanks to intense creative operation of industrial and technological services of a factory of origin headed by I.K. Rostovtsev, S.A. Murygin, M.F. Chalajdjuk, J.V. Karpilovich, and A.M. Titov. The mechanization and the automation of production were possible due to a wide application of conveyer and product lines. Their constant upgrade and application of advanced technologies had made the Minsk factory of G.K. Ordzhonikidze, and then the Minsk production association, a leader of the domestic computer industry. 
In 1970, the USSR proclaimed a state award to the collective of developers and manufacturers of Minsk computers for producing more than 4,000 computers, which was more than $70 \%$ of all computers in the country. The laureates were V.V. Przhijalkovsky, G.P. Lopato, J.G. Bostandzhjan, G.D. Smirnov, N.A. Maltsev, G.K. Stoljarov, I.K. Rostovtsev, M.E. Ekelchik, J.V. Karpilovich, and L.I. Shunjakov.

\section{References}

1. Korolev L.N.: Structures of the computer and their mathematical providing. PH. Nauka (1974)

2. Golubintsev, V.O., Kupaev, V.M., Sinelnikov, E.M.: Evolution of universal computers. The Soviet Radio, Moscow (1980)

3. Przhijalkovsky V.V.: A construction and service characteristics of computer Minsk-2. PH. Statistics, Moscow (1964)

4. Margolin, M.S., Nadenenko, V.K., Smirnov, G.D.: Electronic computer Minsk-22. PH. The Higher school, Minsk (1967)

5. Margolin, M.S., Skoromnik, M.G., Stoljarov, G.K.: Chuprigina L.G. Principle of operation of computer Minsk-23. Statistics, Moscow (1970)

6. Przhijalkovsky, V.V., Smirnov, G.D., Pyhtin, V.J.: Electronic computer Minsk-32 PH. Statistics, Moscow (1972)

7. Lopato, G.P.: Computer techniques in Belarus. IT and VC (January 1997)

8. Minsk, NIIEVM, MPO VT,

http: / / www. Computer-museum.ru/Thecomputerfamily 